\title{
Effect of iron supplementation on glucose transporter 4 expression in adipose tissue and skeletal muscle of pregnant rats
}

\author{
Mulan He, Jing Jiang, Shuangping Liu, Haidong Cheng* \\ Department of Obstetrics, Obstetrics and Gynecology Hospital, Fudan University, Shanghai, China \\ Email: ${ }^{*}$ hdcheng_2003@163.com \\ Received 16 June 2013; revised 14 July 2013; accepted 21 July 2013 \\ Copyright (C) 2013 Mulan He et al. This is an open access article distributed under the Creative Commons Attribution License, which \\ permits unrestricted use, distribution, and reproduction in any medium, provided the original work is properly cited.
}

\begin{abstract}
Objective: The main goal of the present study was to investigate the effect of iron supplementation on glucose transporter 4 expressions in adipose tissue and skeletal muscle in female rats during pregnancy. Methods: Twenty-four pregnant Sprague-Dawley rats were randomly divided into 2 groups: a control group with a standard diet (containing iron $150 \mathrm{mg} / \mathrm{kg}$ ) and an iron-supplementation group with a high-iron diet (containing iron $700 \mathrm{mg} / \mathrm{kg}$ ) from day 0 to day 21 of pregnancy. Intraperitoneal glucose tolerance test was performed on gestational day 19 . On gestational day 21, all of the pregnant rats from each group were sacrificed. The mean neonatal weights were measured and samples of maternal intraabdominal adipose tissue and skeletal muscle were taken to measure the expression of Glucose Transporter 4 (GLUT4) mRNA and protein. Results: Glucose tolerance decreased significantly in the iron supplementation group compared to the control group. The mean neonatal weights in the iron supplementation group were higher than that in the control group. Levels of GLUT4 mRNA in the adipose tissue were reduced by the administrations of high-iron diet. The skeletal muscle GLUT4 mRNA levels were not changed significantly by iron supplementation. Expression of GLUT4 protein both in the adipose tissue and skeletal muscle reduced significantly. Conclusion: These results suggest that iron supplementation during pregnancy would increase neonatal weights and could decrease maternal glucose tolerance by interfering GLUT4 expression in adipose tissue and skeletal muscle of rats.
\end{abstract}

Keywords: Iron; Diabetes; Gestational; Insulin

\footnotetext{
"Corresponding author.
}

Resistance; Glucose Transporter Type 4 (GLUT4); Rats

\section{INTRODUCTION}

The necessity for prophylactic iron supplementation during pregnancy is controversial. Iron requirement in creases during pregnancy, and the body's iron store is often insufficient to meet the demands [1]. Observational studies have produced conflicting results concerning the routine iron supplementation during pregnancy [2]. Past studies prefer to report an association between iron-deficiency anemia (IDA) and adverse obstetrical outcomes such as low gestational weight gain, premature delivery, low birth weight and fetal death [3]. Indirect evidence also suggests that gestation IDA may have a negative impact on neurophysiological outcomes in infants [4]. The routine iron supplementation during pregnancy to prevent IDA is therefore warranted.

However, increasing evidences suggest that iron, a transitional metal and a strong pro-oxidant, influences glucose metabolism, even in the absence of significant iron overload [5]. Large prospective cohort studies found that dietary iron intake, particularly heme iron derived from meat, was associated with a significant increased risk of type 2 diabetes [6]. Furthermore, healthy women with high concentrations of serum ferritin (a biomarker of body iron stores) have been found nearly 3 times more likely to develop type 2 diabetes over a 10 -year period [7]. Although there have been several studies investigating the possible role of dietary and serum ferritin levels on glucose metabolism, only a few studies are available about association between iron supplementation and gestational diabetes mellitus (GDM). Lao et al. [8-10] have found increased serum ferritin concentrations and higher maternal hemoglobin as independent risk factors for GDM, while iron deficient anemia was a protective condition. Indeed, whether iron supplementation is nec- 
essary or toxic; whether it is necessary to both mothers who are deemed to be iron deficient and have normal iron stores (i.e. ferritin $>20 \mu \mathrm{g} / \mathrm{L}$, hemoglobin $>110 \mathrm{~g} / \mathrm{L}$ ) remains controversial.

It has been reported that glucose uptake is mediated by a family of glucose transport proteins, which were found to be expressed in specific tissues. Among these proteins, glucose transporter 4 (GLUT4) is the major glucose transporter isoform in tissues that exhibit insulin-stimulated glucose uptake, such as adipose tissue and skeletal muscle. Insulin stimulates glucose transport in these two tissues by eliciting the translocation of GLUT4 from an intracellular pool to the plasma membrane [11]. Furthermore, defects at the level of GLUT4 expression have been observed in skeletal muscles and adipose tissue of subjects with type 2 diabetes and GDM [12,13]. Thus, GLUT4 defects in insulin target tissues might reflect the situation of whole-body insulin resistance during pregnancy, which is a major factor in the pathogenesis of GDM [14,15].

Since the pregnancy state, itself, leads to insulin resistance [16], it is important to establish the safety of iron supplement in pregnancy, particularly when there are suggestions that increased iron load would further increase insulin resistance $[17,18]$. Hence, in the present study, we evaluated changes in the expression of GLUT4 mRNA and protein in adipose tissue and skeletal muscle of pregnant rats with or without iron supplementation to investigate the association between iron supplementation and the risk of development of GDM. This would help understanding of the causal relationship between increased iron store and diabetes as well as in providing some evidences for the safety of iron supplement in pregnancy in terms of development of GDM.

\section{MATERIALS AND METHODS}

\subsection{Animals and Diet}

Thirty female Sprague-Dawley rats aged 4 weeks (weight $100 \mathrm{~g} \pm 10 \mathrm{~g}$ ) purchased from the National Academy of Science in China. Throughout the experiment, all of the rats were maintained under a controlled environment with 12 hour light/dark cycles and a temperature of $24^{\circ} \mathrm{C}$ $\pm 2^{\circ} \mathrm{C}$. This study was conducted in accordance with the standards established by the Guideline for the Care and Use of Laboratory Animals of Chinese Institute of Health.

All rats consumed the basic diet ad libitum and had free access to distilled deionized water for six weeks. At ten weeks of age, the rats were housed at two females per male for mating. We considered the day sperm-positive smears were obtained to be gestation day (GD) 0 . Twenty-four rats (weight $250 \mathrm{~g} \pm 20 \mathrm{~g}$ ) were pregnant and housed in plastic cages, four rats per cage. Three cages of pregnant rats were allotted randomly to either a control group with basic diet (Diet MO1-F, SLRC Laboratory Animal Co. Ltd., Shanghai, China) containing $150 \mathrm{mg}$ of iron $/ \mathrm{kg}$ of diet or an iron supplementation group with high-iron diet from a mixture of $0.3 \%$ Ferrous Lacate(C6H10FeO63H2O) (GaoYou Sunshine Biochem Co. Ltd, China) and basic diet, resulting in $700 \mathrm{mg}$ of iron $/ \mathrm{kg}$ of diet. Pregnant rats were fed the diets throughout pregnancy. Feed intakes were recorded every five days for each cage through the period of diet intervention. Feed intakes were based on three replicates of four rats each, and body weight data were based on 12 rats per group. Body weights of maternal rats were measured every week. At birth, the number of pups bore per litter and the neonatal weight were measured.

\subsection{Sample Preparation}

The operation of animals was performed under general anesthesia with $10 \%$ chloral hydrate on gestational day 21. The newborn rats weigh respectively. Samples of maternal intraabdominal adipose tissue and femoral quadriceps red muscle were taken, frozen immediately and then stored at $-80^{\circ} \mathrm{C}$ until the RNA and protein were extracted.

\subsection{Intraperitoneal Glucose Tolerance Test (IPGTT)}

Intraperitoneal glucose tolerance test was performed after overnight $(12 \mathrm{~h}-14 \mathrm{~h})$ fasting on GD19. A 50\% glucose solution ( $2 \mathrm{~g} / \mathrm{kg}$ body weight) was intraperitoneally injected to induce hyperglycemia and blood glucose levels were measured at 0, 15, 30, 60 and $120 \mathrm{~min}$. Blood samples were taken from the tail vein and blood glucose levels were determined by means of the glucose oxidase method with a glucose analyzer (Accu-Chek Active, Rothe Diagnostics) according to manufacturer's instructions.

\subsection{RNA Extraction and Reverse Transcription Polymerase Chain Reaction}

Total RNA was isolated from about $5 \mathrm{~mm}^{3}$ fresh rat tissues using TRIzol reagent (Invitrogen, Carlsbad, CA) according to the manufacturer's instructions. The RNA concentration of each solution was determined by measuring its absorbance at $260 \mathrm{~nm}$ and the RNA solutions were stored at $-80^{\circ} \mathrm{C}$ until assayed. The $260 / 280 \mathrm{~nm}$ absorbance ratio of every sample was almost 2.0.

The cDNA was synthesized from $1 \mu \mathrm{g}$ of total RNA by reverse transcriptions. Relative transcript abundance of GLUT4 was analyzed by semi-quantitative reverse transcription polymerase chain reaction (RT-PCR) using GAPDH as an internal standard. The synthetic oligonucleotides used to amplify respective cDNA probe are listed in Table 1. 
The amount of template cDNA and the number of cycles were determined experimentally of so that quantitative comparison could be made during the exponential phase of the amplification process for both target and reference gene. In this experiment, $10 \mu \mathrm{l}$ PCR amplification of the single-strand cDNA was performed by a force-denaturation step of $3 \mathrm{~min}$ at $94^{\circ} \mathrm{C}$, followed by 28 cycles of denaturation $30 \mathrm{sec}$ at $94^{\circ} \mathrm{C}$, annealing $30 \mathrm{sec}$ at $61^{\circ} \mathrm{C}$, and elongation $30 \mathrm{sec}$ at $72^{\circ} \mathrm{C}$, finally extension 5 min at $72^{\circ} \mathrm{C}, 4^{\circ} \mathrm{C}$ hold. PCR products were separated on $2 \%$ agarose gels (Oxiod), which were stained with ethidium bromide. A single band for each gene was observed and photographed at the expected size. The ratio of the intensity of GLUT4 to GAPDH was taken as the transcriptional level of interest. All assays were performed three times on the same sample for each animal. The intra-assay coefficient of variation was $<5 \%$.

\subsection{Western Blot Analysis}

Western blot analysis was conducted to examine the protein expressions of GLUT4 in the adipose tissue and skeletal muscle samples, which were frozen in liquid nitrogen and grinded into debris. The samples were lysed in radio immuno precipitation assay (RIPA) buffer containing $1 \mathrm{mmol} / \mathrm{L}$ phenyl methyl sulfonyl fluoride (PMSF). Insoluble debris was removed by centrifugation at $1000 \mathrm{~g}$ for 15 minutes. Protein concentration were determined by the bicinchoninic acid (BCA) method protein assay reagent kit (Beyotime Institute of Biotechnology, China), using bovine serum albumin (BSA) as the standard. Total proteins $(30 \mu \mathrm{g})$ were separated by $12 \%$ sodium dodecyl sulfate polyacrylamide gels electrophoresis (SDS-PAGE) at $100 \mathrm{~V}$ for $2 \mathrm{~h}$ and electro transferred to polyvinylidene difluoride (PVDF) membranes membranes (Millipore, Bedford, MA) at $300 \mathrm{~mA}$ for $2 \mathrm{~h}$. After blocking in PBS $/ 0.1 \%$ Tween-20 (PBST) with $10 \%$ no fat dry milk for $1 \mathrm{~h}$ at room temperature, membranes were incubated with a 1:200 dilution of mouse anti-rat GLUT4 monoclonal antibody (R \& D Systems, Inc) and a 1:1000 dilution of rabbit antimouse GAPDH antibody (Beyotime Institute of Biotechnology, China) overnight at $4^{\circ} \mathrm{C}$, respectively. Finally, membranes were incubated with a 1:5000 dilution of goat anti mouse or rabbit $\mathrm{IgG}$, horseradish peroxidase conjugated antibody (Beyotime Institute of Biotechnology, China) for $1 \mathrm{~h}$ at room temperature after washing with PBST. Proteins were visualized by enhanced chemiluminescence reagents (Tiangen, Beijing, China).

Protein expression was semi-quantified using Image analysis system (Tiannen, Shanghai, China). All blotting experiments were repeated at least three times, and representative data are shown.

\subsection{Statistical Methods}

All values are presented as the mean \pm standard error (SE). A t test (two tailed) was used to compare difference between iron supplementation and control groups. Date analyses were performed using the computer-based software (SPSS 16.0 for Windows). Statistical significance was considered at the level of $\mathrm{P}<0.05$.

\section{RESULT}

\subsection{Feed Intake, Body Weight Gain and Information of Neonatal Rats}

To examine whether feed intake influenced the accuracy of experimental results, feed intakes of pregnant rats in two groups were measured every five days, namely, GD $1,6,11,16$ and 21. We didn't find significant difference in mean daily feed intakes between two groups $(P>0.05)$ (Figure 1(a)), but the median increase of maternal weight per week in the iron supplementation group was significantly higher than that in the control group $(P<$ 0.01) (Figure 1(b)), suggesting without the influence of feed intake, iron supplementation increased maternal body weight gain during pregnancy.

In addition, there were no significant differences found in the number of pups born per litter between control and iron supplementation group $(\mathrm{P}>0.05)$, however, the median neonatal birth weight in the iron supplementation group were significantly higher than that in the control group $(\mathrm{P}<0.01)$ (Table 2).

\subsection{Intraperitoneal Glucose Tolerance Test (IPGTT)}

The results of IPGTT illustrate the blood glucose profiles

Table 1. The specific primers used in the experiment.

\begin{tabular}{|c|c|c|c|}
\hline \multirow{2}{*}{ Genes } & \multirow{2}{*}{$\operatorname{Primers}\left(5^{\prime}-3^{\prime}\right)$} & Annealing temperature & Product base pairs \\
\hline & & $\left({ }^{\circ} \mathrm{C}\right)$ & (bp) \\
\hline GLUT4 & $\begin{array}{l}\text { P1': }{ }^{\text {a' }} \text {-GGG CTG TGA GTG AGT GCT TTC-3' } \\
\text { P2 }{ }^{\text {b }} \text { : 5'-CAG CGA GGC AAG GCT AGA-3' }\end{array}$ & 55 & $150 \mathrm{bp}$ \\
\hline GAPDH & $\begin{array}{l}\text { P1: 5'-TGC TGG GGC TGG CAT TGC TC-3' } \\
\text { P2: 5'-TCC TTG CTG GGC TGG GTG GT-3' }\end{array}$ & 59 & $150 \mathrm{bp}$ \\
\hline
\end{tabular}

\footnotetext{
${ }^{\mathrm{a}}$ : sense primer; ${ }^{\mathrm{b}}$ : antisense primer.
} 


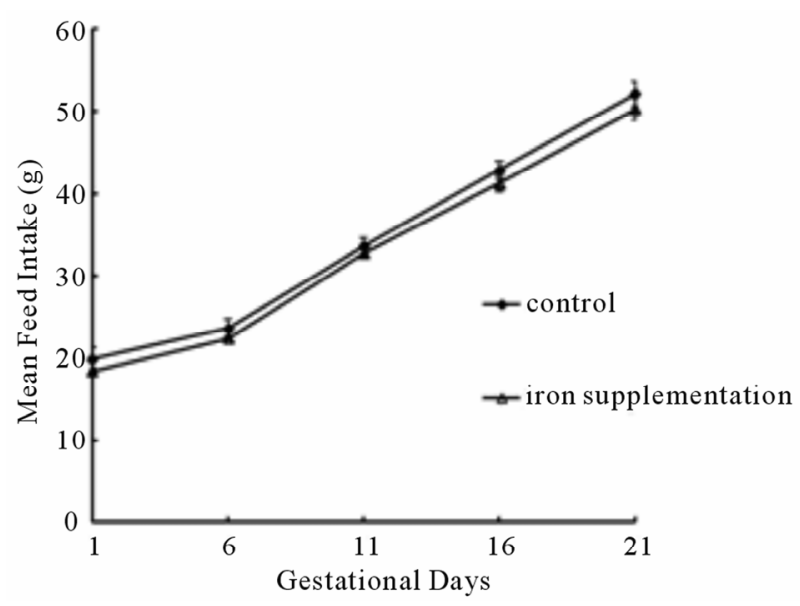

(a)

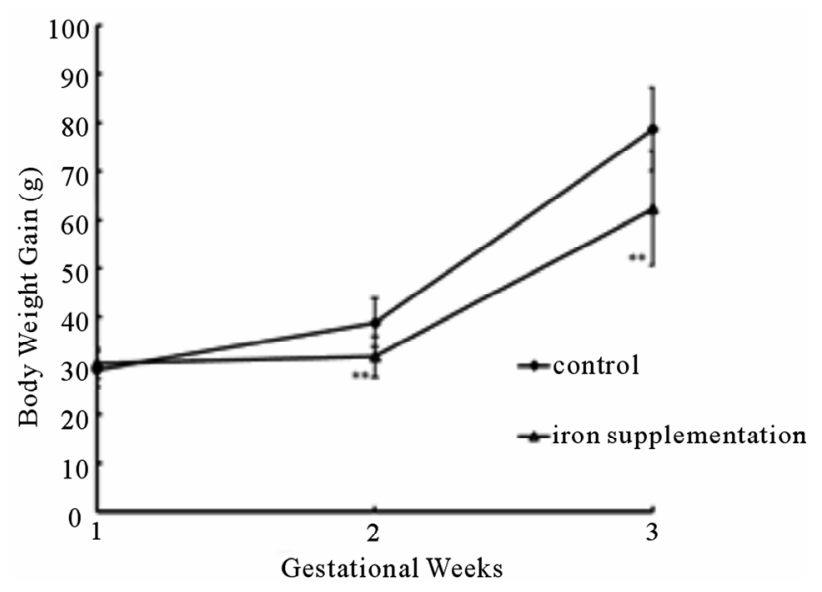

(b)

Figure 1. Mean $\pm \mathrm{SE}$ offeed intake and body weight gain of pregnant rats in two groups during perinatal period. (a) Means daily feed intakes were comparable between control and iron supplementation rats $(P>0.05)$. (b) Means weekly body weight gains of iron supplementation rats were significantly higher than that of control rats $(P<0.01){ }^{* *} P<0.01$ versus control group.

Table 2. Effect of iron supplementation on the number of pups born per litter and neonatal weight.

\begin{tabular}{cccc}
\hline Group & $\mathrm{n}$ & Pups born/litter & $\begin{array}{c}\text { Neonatal } \\
\text { weight }(\mathrm{g})\end{array}$ \\
\hline Control & 12 & $9.0 \pm 1.56$ & $6.1 \pm 0.28$ \\
$\begin{array}{c}\text { Iron } \\
\text { supplementation }\end{array}$ & 12 & $8.7 \pm 2.58$ & $6.7 \pm 0.14^{* *}$ \\
\hline
\end{tabular}

Values are expressed as mean $\pm \mathrm{SE} ;{ }^{* *} P<0.01$ versus control group.

of pregnant rats in the iron supplementation group and control group on GD19. As indicated, rats with iron supplement showed the similar blood glucose concentration after overnight fasting $(0 \mathrm{~min})$ with control rats, but the subsequent glucose levels were significantly higher than control rats (Figure 2). These results reflect that iron supplementation during perinatal period could cause a disturbance in glucose utilization.

\subsection{GLUT4 Messenger RNA Expression Level}

The GLUT4 messenger ribonucleic acid (mRNA) expression in adipose tissue and skeletal muscle samples was evaluated by reverse transcriptase polymerase chain reaction (RT-PCR). In adipose tissue (Figure 3(a)), GLUT4 mRNA expressed in the iron supplementation group was much lower than that in the control group $(\mathrm{P}<$ $0.01)$. However, such expression was not detected in skeletal muscle (Figure 3(b)).

\subsection{GLUT4 Protein Expression Level}

Protein expression in each sample was quantified. From the analysis using Western blot, the similar pattern of GLUT4 protein expression to that of GLUT4 mRNA by RT-PCR was also recorded in adipose tissue (Figure 4(a)). Interestingly, in skeletal muscle, the GLUT4 protein expression levels in the iron supplementation group were also significantly lower than that in the control group (Figure 4(b)), which were unparalleled to the results of RT-PCT analysis.

\section{DISCUSSION}

Iron supplementation during pregnancy has been proven to be beneficial to both mother and fetus [19], enhancing the iron stores in advance, to alleviate further iron losses that could occur during delivery or lactation [20]. However, increasing studies have found positive associations

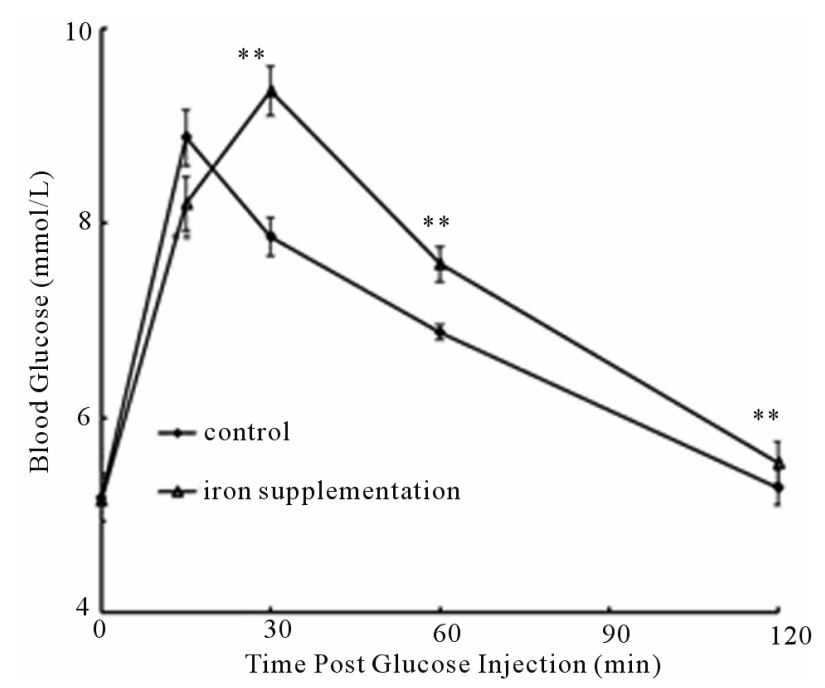

Figure 2. IPGTT of pregnant rats in two groups on GD19. Blood glucose profiles of pregnant rats with iron supplement $(\triangle ; n=12)$ in comparison to glucose clearances of rats with basic diet $(\diamond ; \mathrm{n}=12)($ Mean $\pm \mathrm{SE}) .{ }^{* *} \mathrm{P}<0.01$ versus control group. 


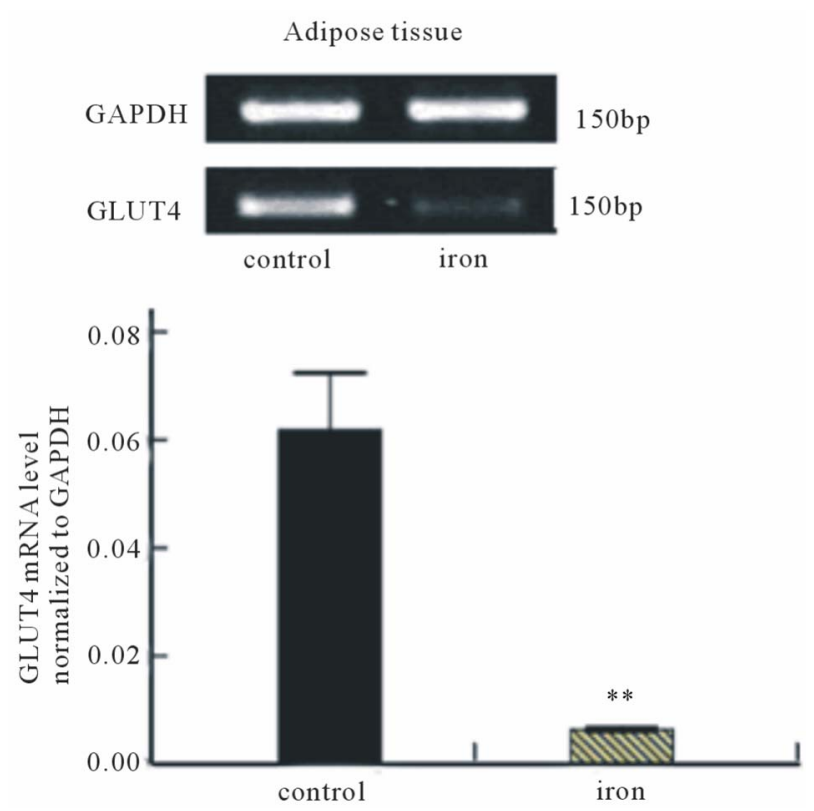

(a)

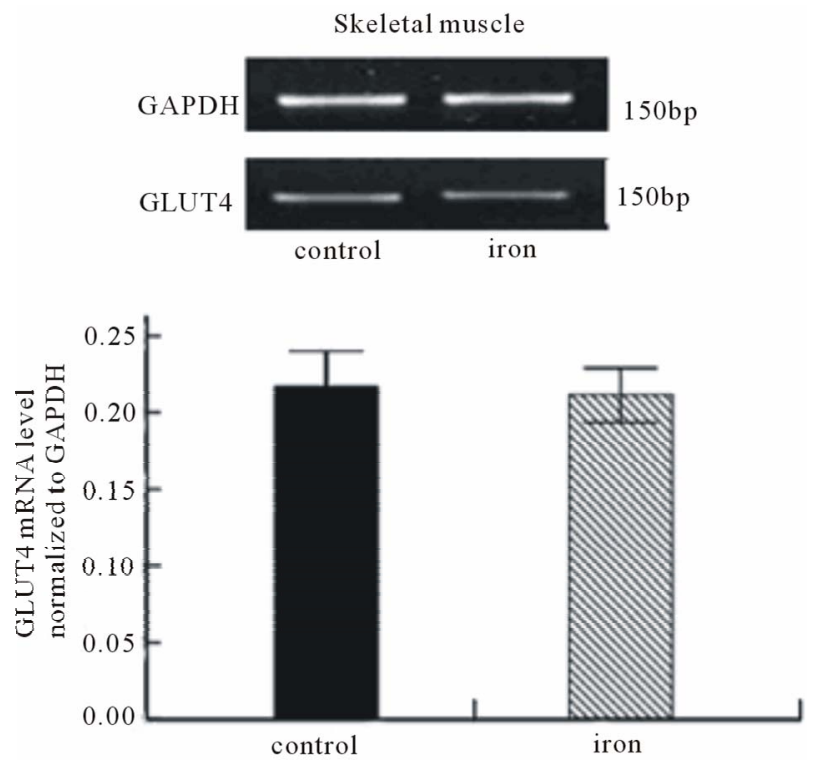

(b)

Figure 3. Effect of iron supplementation during perinatal period on GLUT4 mRNA in (a) adipose tissue $(n=12)$ and (b) skeletal muscle $(n=12)$ of experimental rats. At the top, a representative agarose gel showing PCR analysis for GLUT4 and GAPDH content in adipose tissue and skeletal muscle of one rat is depicted. The PCR analysis was performed three times on the same sample from each of the 24 rats. Bars represent the mean \pm SE values. ${ }^{* *} P<0.01$ versus control group.

between elevated body iron stores and development of type 1 and type 2 diabetes [21], other insulin resistant states such as metabolic syndrome and gestational diabetes [22-25].

In the present study, there were no significant differences in food intakes between iron supplementation and
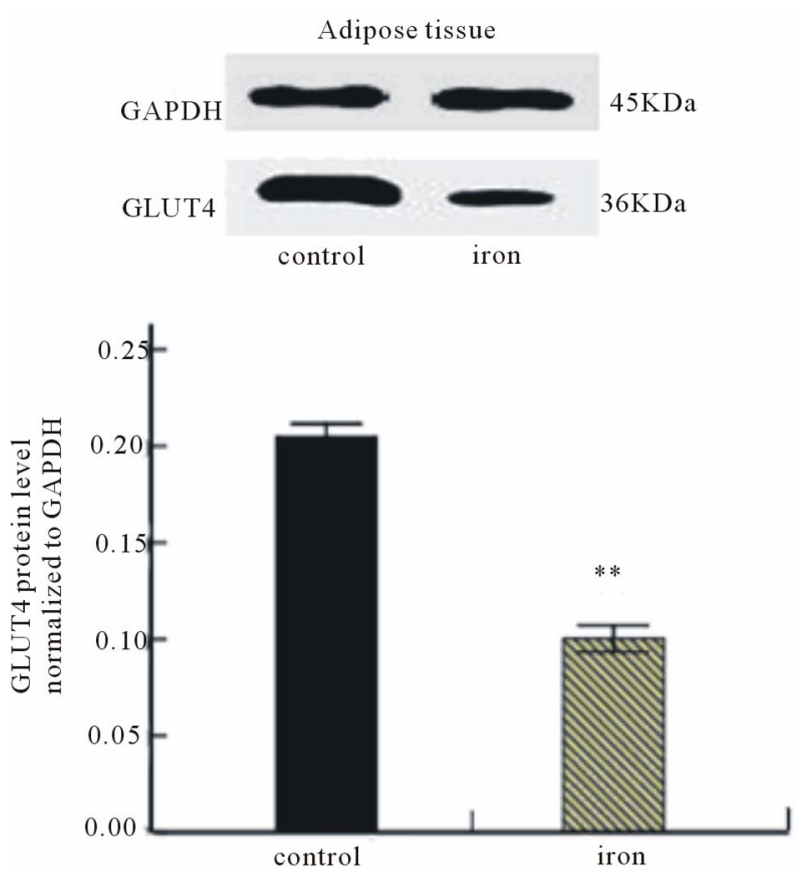

(a)
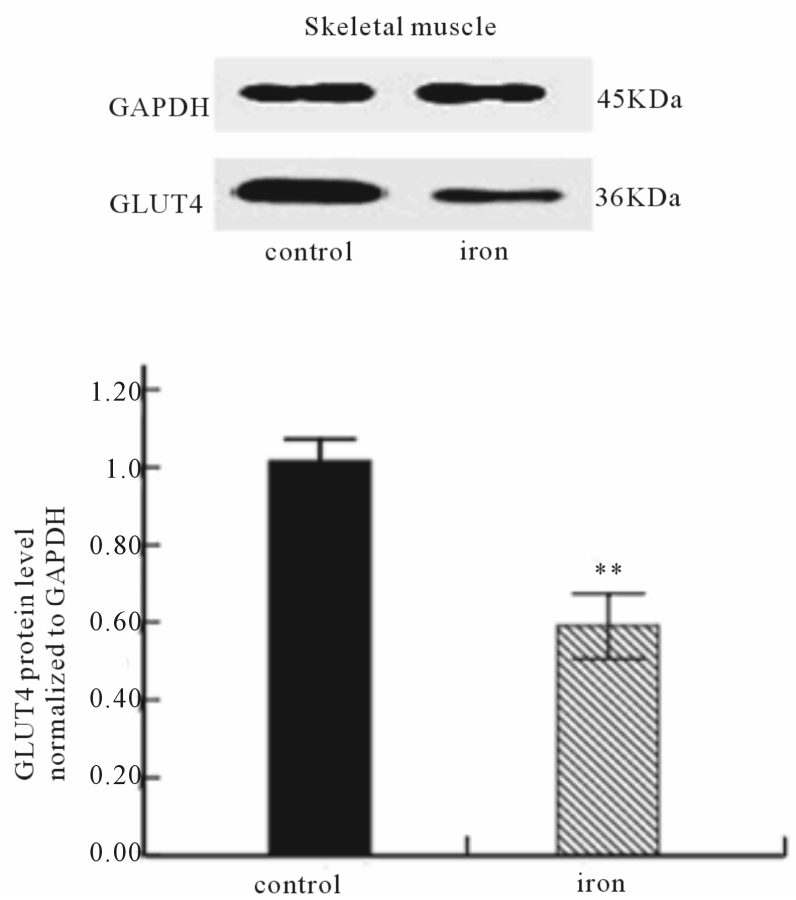

(b)

Figure 4. Effect of iron supplementation during perinatal period on GLUT4 protein in (a) adipose tissue $(n=12)$ and $(b)$ skeletal muscle $(\mathrm{n}=12)$ of experimental rats. At the top, a representative autoradiograph of Western blot analysis for GLUT4 and GAPDH content in adipose tissue and skeletal muscle is depicted. The analysis was performed three twice on the same sample from each of the 24 rats. Bars represent the mean \pm SE values. ${ }^{* *} P<0.01$ versus control group.

control groups, suggesting that feed intake did not influ- 
ence the accuracy of subsequent experimental results, allowing us to use this rat model for the evaluation of the effect of iron supplementation on glucose metabolism during pregnancy.

Previous studies have shown that glucose tolerance is decreased by iron supplementation and is increased by iron depletion [26,27]. In our study, the results of IPGTT demonstrate that iron supplementation during perinatal period has a disturbance in glucose uptake and utilization, resulting in impaired glucose tolerance in pregnant rats.

The results of RT-PCR indicated that iron supplementation during pregnancy significantly reduced GLUT4 mRNA transcription in adipose tissue, but did not change transcription in skeletal muscle. Recently, several laboratories have provided evidences supporting a model for dysregulation of lipid metabolism as a cause of insulin resistance [28,29]. Because the level of GLUT4 expression may play a role in chronic insulin resistance, it seems likely that changes in lipid metabolism could regulate GLUT4 transcription and contribute to downregulation of GLUT4 mRNA. In our experimental conditions we observed that GLUT4 transcription was differentially regulated in adipose tissue compared with skeletal muscle. This difference indicated the existence of tissue-specific regulation. The phenomenon has been observed in many different models of diabetes, obesity and insulin resistance [30,31].

It has been proved that expression and translocation of GLUT4 are crucial to an effective insulin-induced glucose uptake by muscle and adipose cells [32]. Our results demonstrated a decreased expression of GLUT4 protein both in adipose tissue and skeletal muscle of pregnant rats with iron supplementation, whose glucose tolerance also obviously declined in compare with rats in the control group. These results suggest that iron supplementation during pregnancy might diminish insulin-induced glucose uptake in adipose tissue and skeletal muscle by interfering the expression of GLUT4 protein. Another important point is the reduction of GLUT4 protein content observed in skeletal muscle of iron supplementation rats, without parallel reduction in GLUT4 mRNA, suggesting the occurrence of post-transcriptional regulation $[33,34]$.

A number of mechanisms could explain the glycometabolism disorder due to iron supplementation. Iron promotes formation of hydroxyl radicals that can attack cell membranes and affect insulin synthesis and secretion in the pancreas and interferes with the insulin-extracting capacity of the liver $[35,36]$. Peripherally, iron deposition in muscle decreases glucose uptake because of muscle damage [37]. Furthermore, insulin stimulate cellular iron uptake [38], resulting in a vicious cycle, leading to insulin resistance and diabetes. Therefore, declined expression of GLUT4 in adipose tissue and skeletal muscle as we observed can be possibly explained by increased insulin resistance as a result of increased iron load.

We also found that the maternal body weight gain of control rats was greater than iron supplemental rats. In addition, the media neonatal weights in the iron supplementation group were significantly higher than that in the control group, although the number of pups born per litter was similar in two groups. These findings are in agreement with previous studies [3]

According to our results, we consider that if supplemental iron causes maternal iron excess and is in association with insulin resistance or even the occurrence of GDM, the need for revising iron doses and schemes of supplementation during pregnancy and adjust preventive iron supplementation recommendations [39]. Since iron supplementation can really prevent IDA during perinatal period, we think it is important to determine iron status of the pregnant woman first and then to decide whether iron supplementation is necessary. Additional studies are required to better characterize the role of iron supplementation during perinatal period in the regulation of glucose metabolism and in the pathogenesis of GDM.

\section{CONCLUSIONS}

In conclusion, our results demonstrate that iron supplementation during pregnancy could decrease glucose tolerance by interfering GLUT4 expression in adipose tissue and skeletal muscle of rats, may resulting in insulin resistance, even the occurrence of GDM. It is necessary to exercise caution in the use of iron supplementation during pregnancy.

\section{ACKNOWLEDGEMENTS}

The authors thank Mingjun Cheng Ph.D. for early contributions to the study and Obstetrics and Gynecology Research Institute of Fudan University for maintaining the animal facilities.

\section{REFERENCES}

[1] Bothwell, T.H. (2000) Iron requirements in pregnancy and strategies to meet them. American Journal of Clinical Nutrition, 72, 257S-263S.

[2] Habib, F., Alabdin, E.H.Z., Alenazy, M. and Nooh, R. (2009) Compliance to iron supplementation during pregnancy. Journal of Obstetrics and Gynaecology, 29, 487492. doi:10.1080/01443610902984961

[3] Cogswell, M.E., Parvanta, I., Ickes, L., Yip, R. and Brittenham, G.M. (2003) Iron supplementation during pregnancy, anemia, and birth weight: A randomized controlled trial. American Journal of Clinical Nutrition, 78, 773-781.

[4] Rioux, F.M., Lindmark, G. and Hernell, O. (2006) Does inadequate maternal iron or DHA status have a negative impact on an infant's functional outcomes? Acta Paedi- 
atrica, 95, 137-144. doi:10.1080/08035250500281814

[5] Rajpathak, S.N., Crandall, J.P., Wylie-Rosett, J., Kabat, G.C., Rohan, T.E. and Hu, F.B. (2009) The role of iron in type 2 diabetes in humans. Biochimica et Biophysica Acta (BBA)-General Subjects, 1790, 671-681. doi:10.1016/j.bbagen.2008.04.005

[6] Luan, D.C., Li, H., Li, S.J., Zhao, Z., Li, X. and Liu, Z.M. (2008) Body iron stores and dietary iron intake in relation to diabetes in adults in north China. Diabetes Care, 31, 285-286. doi:10.2337/dc07-0921

[7] Jiang, R., Manson, J.E., Meigs, J.B., Ma, J., Rifai, N. and $\mathrm{Hu}$, F.B. (2004) Body iron stores in relation to risk of type 2 diabetes in apparently healthy women. Jama-Journal of the American Medical Association, 291, 711-717. doi:10.1001/jama.291.6.711

[8] Lao, T.T., Tam, K.F. and Chan, L.Y. (2000) Third trimester iron status and pregnancy outcome in non-anaemic women; pregnancy unfavourably affected by maternal iron excess. Human Reproduction, 15, 1843-1848. doi:10.1093/humrep/15.8.1843

[9] Lao, T.T., Chan, L.Y., Tam, K.F. and Ho, L.F. (2002) Maternal hemoglobin and risk of gestational diabetes mellitus in Chinese women. Obstetrics and Gynecology, 99, 807-812. doi:10.1016/S0029-7844(02)01941-5

[10] Lao, T.T. and Ho, L.F. (2004) Impact of iron deficiency anemia on prevalence of gestational diabetes mellitus. Diabetes Care, 27, 650-656. doi:10.2337/diacare.27.3.650

[11] Charron, M.J., Katz, E.B. and Olson, A.L. (1999) GLUT4 gene regulation and manipulation. Journal of Biological Chemistry, 274, 3253-3256. doi:10.1074/jbc.274.6.3253

[12] Yamada, K., Yamakawa, K., Terada, Y., Kawaguchi, K., Sugaya, A., Sugiyama, T. and Toyoda, N. (1999) Expression of GLUT4 glucose transporter protein in adipose tissue and skeletal muscle from streptozotocin-induced diabetic pregnant rats. Hormone and Metabolic Research, 31, 508-513.

[13] Okuno, S., Akazawa, S., Yasuhi, I., Kawasaki, E., Matsumoto, K., Yamasaki, H., Matsuo, H., Yamaguchi, Y. and Nagataki, S. (1995) Decreased expression of the glut4 glucose-transporter protein in adipose-tissue during pregnancy. Hormone and Metabolic Research, 27, 231234. doi:10.1055/s-2007-979946

[14] Smirnakis, K.V., Martinez, A., Blatman, K.H., Wolf, M., Ecker, J.L. and Thadhani, R. (2005) Early pregnancy insulin resistance and subsequent gestational diabetes mellitus. Diabetes Care, 28, 1207-1208. doi:10.2337/diacare.28.5.1207

[15] Colomiere, M., Permezel, M. and Lappas, M. (2010) Diabetes and obesity during pregnancy alter insulin signalling and glucose transporter expression in maternal skeletal muscle and subcutaneous adipose tissue. Journal of Molecular Endocrinology, 44, 213-223. doi:10.1677/JME-09-0091

[16] Stanley, K., Fraser, R. and Bruce, C. (1998) Physiological changes in insulin resistance in human pregnancy: Longitudinal study with the hyperinsulinaemic euglycaemic clamp technique. British Journal of Obstetrics and Gy- naecology, 105, 756-759.

doi:10.1111/j.1471-0528.1998.tb10207.x

[17] Martinez-Garcia, M.A., Luque-Ramirez, M., San-Millan, J.L. and Escobar-Morreale, H.F. (2009) Body iron stores and glucose intolerance in premenopausal women role of hyperandrogenism, insulin resistance, and genomic variants related to inflammation, oxidative stress, and iron metabolism. Diabetes Care, 32, 1525-1530. doi: $10.2337 / \mathrm{dc} 09-0420$

[18] Le Guenno, G., Chansaume, E., Ruivard, M., Morio, B. and Mazur, A. (2007) Study of iron metabolism disturbances in an animal model of insulin resistance. Diabetes Research and Clinical Practice, 77, 363-370. doi:10.1016/j.diabres.2007.02.004

[19] Menendez, C., Todd, J., Alonso, P.L., Francis, N., Lulat, S., Ceesay, S., Mboge, B. and Greenwood, B.M. (1994) The effects of iron supplementation during pregnancy, given by traditional birth attendants, on the prevalence of anemia and malaria. Transactions of the Royal Society of Tropical Medicine and Hygiene, 88, 590-593. doi:10.1016/0035-9203(94)90176-7

[20] Ward, R.J., Wilmet, S., Legssyer, R., Leroy, D., Toussaint, L., Crichton, R.R., Pierreux, C., Hue, L., Piette, J., Srai, S.K., Solanky, N., Klein, D. and Summer, K. (2009) Effects of marginal iron overload on iron homeostasis and immune function in alveolar macrophages isolated from pregnant and normal rats. Biometals, 22, 211-223. doi:10.1007/s10534-008-9155-6

[21] Thomas, M.C., MacIsaac, R.J., Tsalamandris, C. and Jerums, G. (2004) Elevated iron indices in patients with diabetes. Diabetic Medicine, 21, 798-802. doi:10.1111/j.1464-5491.2004.01196.x

[22] Bo, S., Menato, G., Villois, P., Gambino, R., Cassader, M., Cotrino, I. and Cavallo-Perin, P. (2009) Iron supplementation and gestational diabetes in midpregnancy. American Journal of Obstetrics and Gynecology, 201, 6 . doi:10.1016/j.ajog.2009.04.049

[23] Afkhami-Ardekani, M. and Rashidi, M. (2009) Iron status in women with and without gestational diabetes mellitus. Journal of Diabetes and Its Complications, 23, 194-198. doi:10.1016/j.jdiacomp.2007.11.006

[24] Hultcrantz, R. (2006) Iron overload and the metabolic syndrome. Scandinavian Journal of Gastroenterology, 41, 756-759.

[25] Wrede, C.E., Buettner, R., Bollheimer, L.C., Scholmerich, J., Palitzsch, K.D. and Hellerbrand, C. (2006) Association between serum ferritin and the insulin resistance syndrome in a representative population. European Journal of Endocrinology, 154, 333-340. doi:10.1530/eje.1.02083

[26] Dongiovanni, P., Valenti, L., Fracanzani, A.L., Gatti, S., Cairo, G. and Fargion, S. (2008) Iron depletion by deferoxamine up-regulates glucose uptake and insulin signaling in hepatoma cells and in rat liver. American Journal of Pathology, 172, 738-747. doi:10.2353/ajpath.2008.070097

[27] Ozyigit, E.A., Ugur, M., Unlu, S., Ozaksit, G. and Avsar, F. (2008) The effect of oral iron supplementation on the glucose metabolism in non-anemic pregnant women: A prospective case-control study. Uhod-Uluslararasi $\mathrm{He}$ - 
matoloji-OnkolojiDergisi, 18, 155-162.

[28] Chibalin, A.V., Leng, Y., Vieira, E., Krook, A., Bjoernholm, M., Long, Y.C., Kotova, O., Zhong, Z.H., Sakane, F., Steiler, T., Nylen, C., Wang, J.J., Laakso, M., Topham, M.K., Gilbert, M., Wallberg-Henriksson, H. and Zierath, J.R. (2008) Downregulation of diacylglycerol kinase delta contributes to hyperglycemia-induced insulin resistance. Cell1, 32, 375-386. doi:10.1016/j.cell.2007.12.035

[29] Holland, W.L., Brozinick, J.T., Wang, L.P., Hawkins, E.D., Sargent, K.M., Liu, Y.Q., Narra, K., Hoehn, K.L., Knotts, T.A., Siesky, A., Nelson, D.H., Karathanasis, S.K., Fontenot, G.K., Birnbaum, M.J. and Summers, S.A. (2007) Inhibition of ceramide synthesis ameliorates glucocorticoid-, saturated-fat-, and obesity-induced insulin resistance. Cell Metabolism, 5, 167-179. doi:10.1016/j.cmet.2007.01.002

[30] Griesel, B.A., Weems, J., Russell, R.A., Abel, E.D., Humphries, K. and Olson, A.L. (2010) Acute inhibition of fatty acid import inhibits GLUT4 transcription in adipose tissue, but not skeletal or cardiac muscle tissue, partly through liver X receptor (LXR) signaling. Diabetes, 59, 800-807. doi:10.2337/db09-1542

[31] Sugaya, A., Sugiyama, T., Yanase, S., Shen, X.X., Minoura, H. and Toyoda, N. (2000) Expression of glucose transporter 4 mRNA in adipose tissue and skeletal muscle of ovariectomized rats treated with sex steroid hormones. Life Sciences, 66, 641-648. doi:10.1016/S0024-3205(99)00636-0

[32] Stenbit, A.E., Tsao, T.S., Li, J., Burcelin, R., Geenen, D.L., Factor, S.M., Houseknecht, K., Katz, E.B. and Charron, M.J. (1997) GLUT4 heterozygous knockout mice develop muscle insulin resistance and diabetes. Nature Medicine, 3, 1096-1101. doi:10.1038/nm1097-1096

[33] Poletto, A.C., Anhe, G.F., Eichler, P., Takahashi, H.K., Furuya, D.T., Okamoto, M.M., Curi, R. and Machado, U.F. (2010) Soybean and sunflower oil-induced insulin resistance correlates with impaired GLUT4 protein ex- pression and translocation specifically in white adipose tissue. Cell Biochemistry and Function, 28, 114-121. doi:10.1002/cbf.1628

[34] Rincon, J., Holmang, A., Wahlstrom, E.O., Lonnroth, P., Bjorntorp, P., Zierath, J.R. and WallbergHenriksson, H. (1996) Mechanisms behind insulin resistance in rat skeletal muscle after oophorectomy and additional testosrone treatment. Diabetes, 45, 615-621. doi:10.2337/diabetes.45.5.615

[35] Cooksey, R.C., Jouihan, H.A., Ajioka, R.S., Hazel, M.W., Jones, D.L., Kushner, J.P. and McClain, D.A. (2004) Oxidative stress, beta-cell apoptosis, and decreased insulin secretory capacity in mouse models of hemochromatosis. Endocrinology, 145, 5305-5312. doi:10.1210/en.2004-0392

[36] Mendler, M.H., Turlin, B., Moirand, R., Jouanolle, A.M., Sapey, T., Guyader, D., Le Gall, J.Y., Brissot, P., David, V. and Deugnier, Y. (1999) Insulin resistance-associated hepatic iron overload. Gastroenterology, 117, 1155-1163. doi:10.1016/S0016-5085(99)70401-4

[37] Huang, J.Y., Jones, D., Luo, B., Sanderson, M., Soto, J., Abel, E.D., Cooksey, R.C. and McClain, D.A. (2011) Iron overload and diabetes risk: A shift from glucose to fatty acid oxidation and increased hepatic glucose production in a mouse model of hereditary hemochromatosis. Diabetes, 60, 80-87. doi:10.2337/db10-0593

[38] McCarty, M.F. (2003) Hyperinsulinemia may boost both hematocrit and iron absorption by up-regulating activity of hypoxia-inducible factor-1 alpha. Medical Hypotheses, 61, 567-573. doi:10.1016/S0306-9877(03)00231-7

[39] Pena-Rosas, J.P. and Viteri, F.E. (2009) Effects and safety of preventive oral iron or iron plus folic acid supplemenion for women during pregnancy. Cochrane Database of Systematic Reviews, 234, D004736. 